\title{
Gaining Access to Major Elective Surgeries in a Public Tertiary Health Institution in Southeast Nigeria: Evaluating Household Payment Coping Strategies
}

\author{
Ikenna Ifeanyi Nnabugwu, ${ }^{1,2}$ Chikezie Nwankwor, ${ }^{1}$ Fredrick Ugwumba ${ }^{1,2}$ \\ ${ }^{1}$ College of Medicine, University of Nigeria Enugu Campus \\ 2 University of Nigeria Teaching Hospital
}

Correspondence to: Dr. Nnabugwu Ikenna, PMB 01129 Ituku-Ozalla; email: ikenna.nnabugwu@unn.edu.ng

\begin{abstract}
Background: The Lancet Commission on Global Health recommends that by 2030 no household should be impoverished while accessing needed surgical operation. Meeting this target in Nigeria is challenging. This study aims to evaluate the payment coping strategies adopted by households in southeast Nigeria in gaining access to needed major surgeries electively. The findings will aid in designing policies towards improving access to needed surgical care. Methods: A hospital-exit cross-sectional survey of households that accessed major surgeries electively from the study health institution from July to December 2017. Payment coping strategies were compared across household wealth quintiles and household characteristics. SPSS ${ }^{\circledR}$ version 20 was used for analysis. Results: Household characteristics associated with deployment of extreme payment coping strategies were: household size $>6$ persons $(\mathrm{p}=0.001)$, female-headed households $(\mathrm{p}=0.001)$ and
\end{abstract}

\section{Introduction}

Gaining access to healthcare services including surgical care remains a dominant feature of discussions on improving health systems worldwide (1). During the 68th World Health Assembly of the World Health Organization (WHO) on 22 May 2015, delegates unanimously adopted "essential surgical care and anaesthesia" as a component of universal health coverage (2). Therefore, in low and medium income countries (LMIC) such as Nigeria where social security infrastructure development is still rudimentary (3), the need is urgent to address financial access to surgical care. Poverty limits household access to curative, rehabilitative and palliative surgical care, posing increased risk of financial hardship or catastrophe upon accessing needed surgical care (4).

In Nigeria, the national strategic health development plan framework 2009-2015 observes that healthcare costs contribute significantly to poor utilization of healthcare services by individuals and households, leading to poor health outcomes, and that poverty is a major factor in decision making by individuals and households on when and how to utilize available healthcare services (4).

Regrettably, more than $90 \%$ of the households in southeast Nigeria do not have any form of social insurance on health and lower formal education of household heads ( $\mathrm{p}=0.004)$, but not household socio-economic status $(\mathrm{p}=0.16)$. Whereas $98.7 \%$ of uninsured households and $88.5 \%$ of insured households drew from household savings, $61.4 \%$ of uninsured households and $26.9 \%$ of insured households deployed further payment coping strategies beyond drawing from savings $(\mathrm{p}=0.05)$. Conclusion: Extreme hardship financing is evidently prevalent among uninsured households accessing major surgical operation electively, irrespective of household socio-economic status.

Key words: Hardship financing, Payment coping strategies, Out-of-pocket payment

Ann Afr Surg. 2019; 16(2):69-74

DOI:http://dx.doi.org/10.4314/aas.v16i2.6

Conflicts of Interest: None

Funding: None

hence purchase healthcare at all times by direct out-of-pocket payment mechanism $(3,5)$. Unlike the prepayment mechanisms of financing healthcare services underpinning the different insurance and tax-based health financing models, direct outof-pocket (OOP) payment makes an unexpected demand on an individual's or a household's income, which very often cannot be met by routine household budget, a situation known as hardship financing of needed medical care. Such hardship financing can occur irrespective of the socio-economic status of the household (6).

Accessing major surgical operations has high cost implications irrespective of the society involved with an estimate of nearly half of the world's population, mostly within sub-Saharan Africa, being at risk of financial catastrophe when in need of surgery $(7,8)$. There is financial catastrophe when more than a reasonable proportion (usually greater than $40 \%$ ) of limited household income after subsistence expenses is spent on accessing needed medical care.

Drawing from savings as a payment coping strategy, where regular household budget becomes inadequate, has been proposed by Madan et al. (9) as a proxy for identifying financial hardship: being predictable, convenient and handy whenever available. However, such drawings from household savings 
may not be readily differentiated from spending from regular household income among the low income households (10). Other payment coping strategies such as borrowing from formal and informal sources, raising funds through sale of valuable assets, taking up extra jobs or working extra hours, forfeiting foods, undue postponement in defraying fees for accessed services, and asking for charity or begging for alms could be used where household savings is non-existent or adjudged to be incapable of addressing the financial concerns of the household (11). Adopting these extreme payment coping strategies arguably points towards deeper financial hardship on households as well as presents longer lasting impoverishing consequences on the household (12).

An insight into the payment coping mechanisms adopted by households to gain access to major surgical operations electively will be of great value in proposing appropriate policies towards achieving the universal health coverage target of eliminating hardship financing of healthcare services by 2030 . The aim of this study is to evaluate the payment coping strategies households deploy to successfully gain access to major surgical operations electively from the University of Nigeria Teaching Hospital, Enugu, southeast Nigeria. Emphasis is on the extreme payment coping strategies deployed by households beyond drawing from household savings. The findings will aid in providing appropriate considerations for policy changes in health system financial risk protection strategies.

\section{Materials and Methods}

This was a hospital-exit quantitative survey of households whose adult members gained access to major elective surgeries from July to December 2017 from the University of Nigeria Teaching Hospital, a public tertiary hospital located in southeast Nigeria. The surgery section of the hospital has 176 lying-in beds. The study population comprised households accessing surgical care in the department of surgery of the health institution; individual households that gave consent for the study constituted the study units. The major surgeries accessed electively were within general surgery, urology, gynaecology and orthopaedic surgery units.

Southeast Nigeria has a projected population of 21 million people with approximately $62 \%$ adults (13). The survey used an exit questionnaire to gather information from every household whose adult household member (patient) accessed major elective surgery within the survey period. Major surgery was defined as a surgical procedure that posed substantive risk to life of the patient, and usually required general anaesthesia or regional anaesthesia. Study questionnaires were administered upon discharge from hospital and complete settlement of hospital bills. Pre-tutored trainee-surgeons, acting as research assistants, administered the questionnaires to the household member who acted as lead caregiver during the period of hospital admission.

The questionnaire had 3 sections: first section sought to identify household characteristics - number of persons in the household (adults and children), gender, age and formal education attainment of head of household. Second section identified the payment method and the payment coping strategies deployed by the household in gaining access to recommended major surgery. The coping strategies captured were drawing from household savings, borrowing, begging for alms, sale of asset(s), forfeiting food, and others to be specified. All strategies beyond drawing from household savings were considered extreme coping strategies. The last section explored household durable assets and living conditions based on Harmonized Nigerian Living Standard Survey 2009/10: core welfare indicator questionnaire survey 2009 (Part A), 14, from which wealth indices were created for determining the socio-economic status quintiles of households. The questionnaire was pretested on 20 households to confirm its ease of administration.

Using Principal Component Analysis (PCA), household durable assets and household living conditions for urban and rural households were aggregated to generate wealth indices from which socio-economic status quintiles were created. The frequencies of adoption of the identified payment coping strategies by the participating households were determined. Crosstab analysis and binary regression analysis were used to identify associations between household characteristics, socio-economic status quintiles, and identified payment coping strategies. Data analysis used IBM ${ }^{\circledR}$ SPSS Statistics version 20. Households that gained access to daycare procedures were excluded because their procedures were billed as minor procedures and there were no ward admission costs. Households that gained access to major surgeries for children were also excluded because medical bills for children are usually 50 $60 \%$ of bills for adults. Similarly, households that accessed emergency surgical operations were excluded because they had no time to plan for the procedure electively.

The health institution's Bioethics Committee approved the study, and a written consent to participate, after due information, was obtained from each of the households that participated.

\section{Results}

Within the study period, 329 adult patients representing same number of households successfully gained access to major elective surgical operations, met other inclusion criteria, and gave informed consent to participate in the study. The mean age of the patients was $39.3 \pm 13.8$ years. Table 1 shows other demographic characteristics of the patients.

Table 2 shows some of the characteristics of the patients' households. 
Table 1. Demographic characteristics of patients who gained access to major elective surgical operations

\begin{tabular}{|c|c|}
\hline Patient demographics & Frequency $n(\%)$ \\
\hline \multicolumn{2}{|l|}{ Gender } \\
\hline Female & $171(52.0)$ \\
\hline Male & $158(48.0)$ \\
\hline \multicolumn{2}{|c|}{ Highest level of formal education attained } \\
\hline Tertiary & $115(35.0)$ \\
\hline Secondary & $163(49.5)$ \\
\hline Primary & 47 (14.3) \\
\hline None & $4(1.2)$ \\
\hline \multicolumn{2}{|l|}{ Marital status } \\
\hline Single & $113(34.3)$ \\
\hline Married & $197(59.9)$ \\
\hline Separated & $2(0.6)$ \\
\hline Divorced & $5(1.5)$ \\
\hline Widowed & $12(3.6)$ \\
\hline \multicolumn{2}{|l|}{ Occupation } \\
\hline Studying & $29(8.8)$ \\
\hline Unemployed & $8(2.4)$ \\
\hline Artisan & $58(17.6)$ \\
\hline Farming & $10(3.0)$ \\
\hline Trading & $115(35.0)$ \\
\hline Informal sector employee & $37(11.2)$ \\
\hline Formal sector employee & $57(17.3)$ \\
\hline Retired & $15(4.6)$ \\
\hline \multicolumn{2}{|l|}{ Payment method } \\
\hline Direct out-of-pocket payment & $303(92.1)$ \\
\hline $\begin{array}{l}\text { National Health Insurance } \\
\text { Scheme }\end{array}$ & $26(7.9)$ \\
\hline $\begin{array}{l}\text { Community-based health } \\
\text { insurance scheme }\end{array}$ & $0(0.0)$ \\
\hline Others & $0(0.0)$ \\
\hline
\end{tabular}

All other coping strategies deployed beyond drawing from household savings were lumped together as extreme coping strategies. Figure 1 compares the proportion of uninsured households against insured households deploying extreme payment coping strategies.

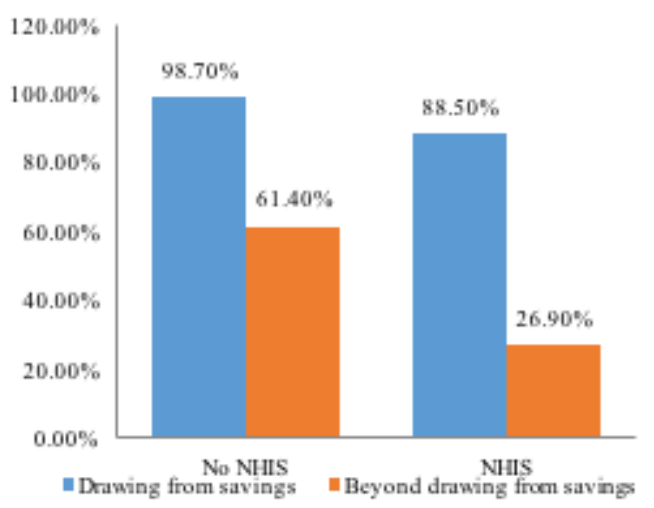

Figure 1. Comparison of deployment of drawing from household savings and deployment of extreme coping strategies by uninsured (No NHIS) and insured (NHIS) households.
Table 2. Summary of some characteristics of participating households $(\mathrm{HH})$

\begin{tabular}{ll}
\hline Household characteristics & Values \\
\hline Mean number of persons per HH & $5.0 \pm 2.1$ \\
Median number of adults $\geq 18$ years in HH & 3.0 (IQR 2.0-5.0) \\
Mean age of $H H$ heads & $51.6 \pm 11.1$ years \\
Male-headed HH & $299(90.9 \%)$ \\
Post-primary education & $235(78.6 \%)$ \\
Health insurance status & $26(8.7 \%)$ \\
No. with size $>6$ persons & $56(18.7 \%)$ \\
No. with with >6 adults & $28(9.4 \%)$ \\
Socioeconomic status quintiles & \\
Q1 (lowermost quintile) & $63(19.3 \%)$ \\
Q2 (lower quintile) & $72(21.9 \%)$ \\
Q3 (low quintile) & $58(17.7 \%)$ \\
Q4 (high quintile) & $71(21.6 \%)$ \\
Q5 (higher quintile) & $65(19.6 \%)$ \\
Female-headed households & $30(9.1 \%)$ \\
Post-primary education & $11(36.7 \%)$ \\
Health insurance status & $0(0.0 \%)$ \\
No. with size $>6$ persons & $5(16.7 \%)$ \\
No. with $>6$ adults & $5(16.7 \%)$ \\
\hline
\end{tabular}

Households that paid entirely out-of-pocket (uninsured) were grouped apart from households that accessed national health insurance (insured) for the needed major surgery. Table 3 compares the proportions of households in the two different groups that deployed various payment coping strategies.

Table 3. Comparison of the frequency distribution of the identified payment coping strategies of households that used direct out-of-pocket payment against households that used the NHIS.

\begin{tabular}{lrrl}
\hline Payment coping strategy & $\begin{array}{l}\text { Freq (\%) } \\
\text { (OOP) } \\
n=306\end{array}$ & $\begin{array}{l}\text { Freq (\%) } \\
\text { (NHIS) }\end{array}$ & p value \\
\hline Savings & 98.7 & 87.0 & 0.01 \\
Begging for alms & 43.1 & 17.4 & 0.02 \\
Borrowing & 42.5 & 0.0 & $<0.001$ \\
Sale of assets & 2.9 & 0.0 & 1.00 \\
Forfeiting food & 4.9 & 0.0 & 0.60 \\
$\begin{array}{l}\text { Postponing fees } \\
\text { Savings and Borrowing }\end{array}$ & 1.6 & 0.0 & 1.00 \\
only & 16.0 & 0.0 & 0.03 \\
$\begin{array}{l}\text { Savings and Charity only } \\
\text { Borrowing and Charity }\end{array}$ & 13.1 & 17.4 & 0.53 \\
only & 0.0 & 0.0 & \\
$\begin{array}{l}\text { Savings and Borrowing } \\
\text { and Charity }\end{array}$ & 24.2 & 0.0 & 0.003 \\
\hline
\end{tabular}

[Freq: Frequency; OOP: out-of-pocket; NHIS: National Health Insurance Scheme; $p$ value: Chi square with Fischer exact test (2-sided)] 
Table 4 shows the relationship between deployment of the further payment coping strategies and household characteristics.

\section{Discussion}

Essential surgery and anaesthesia have been recognized as important aspects to universal health coverage (2). Accessing surgery for surgically amenable disease conditions can drive a household into financial catastrophe in the absence of a robust financial risk protection mechanism (7). This is most likely when the surgical operation accessed is major, and where the household accessing the surgery does so through outof-pocket payment mechanism. Generally, households may have the capacity to pay by direct out-of-pocket (OOP) payment drawn promptly from daily, weekly, or monthly household budget for minor health challenges

(15). However, beyond these minor health challenges, one or more of the socially recognized payment coping mechanisms such as drawing from savings and borrowing are brought to bear by individual households in desperate attempts to cushion the financial hardship upon these households as a result of paying for the needed health care services (16).

Generally, health insurance coverage is quite low in Nigeria, as has been identified from this study, leaving many households with no better alternative to direct out-of-pocket payment mechanism. Olugbenga-Bello and Adebimpe (17) in Osun State, southwestern Nigeria, report that only $0.3 \%$ of 380 respondents accessed NHIS for a health challenge, while from a rural community in Delta State, Nigeria, Dienye et al. (18) report that none of the 229 patients that accessed surgical operation within the 5-year study period did so using any form of prepayment social insurance on health even though $3.06 \%$ of them knew about NHIS. Similarly, Etiaba et al. note that none of the households that accessed malaria treatment from health facilities in two communities in Enugu State, southeast Nigeria, had health insurance coverage (19). The 8\% of households from this study that gained access to national health insurance for their surgeries may not necessarily reflect improved awareness and coverage of the NHIS. A rather plausible explanation, recognizing that the formal sector social health insurance program of the NHIS in Nigeria is the only functional platform to date (4), is that a higher proportion of households of employees of the federal civil service in Nigeria make use of the study health institution.

The mean number of persons in the households interviewed (5.0 \pm 2.1 ; Table 2) is similar to the finding of 4.0 and 4.88 residents per household in other community surveys in Nigeria (20). In contradistinction to the finding of $40 \%$ female-headed households in a community study in Enugu state, Nigeria (5), this study has noted only $9.1 \%$ female-headed households, many of the female heads being the patients themselves. These
Table 4. Analysis of household characteristics relating to deployment of further payment coping strategies beyond drawing from household savings

\begin{tabular}{llll} 
Household characteristics & OR & $95 \%$ Cl of OR & p-value \\
\hline Patient's age $>40$ years & 3.0 & $0.8-11.2$ & 0.10 \\
Male patients & 0.1 & $0.05-0.22$ & $<0.001$ \\
Less educated patients & 0.7 & $0.1-3.5$ & 0.67 \\
Actively employed patients & 2.0 & $0.6-6.7$ & 0.25 \\
Insured households & 0.3 & $0.1-1.0$ & 0.05 \\
Household size $>6$ & 4.7 & $1.8-11.8$ & 0.001 \\
Number of adults $>6$ & 0.1 & $0.05-0.45$ & 0.001 \\
Female household heads & 15.9 & $3.3-75.7$ & 0.001 \\
Less educated household heads & 8.9 & $2.0-38.8$ & 0.004 \\
Household socio-economic status & 0.8 & $0.7-1.1$ & 0.19 \\
\hline
\end{tabular}

[OR: Odds Ratio; CI; Confidence Interval]

female heads are mostly poorly educated. Though female gender per se does not portend restrained household financial capacity, its association with poorer formal education, single parenthood and absence of any form of health insurance cover increases the odds of such female-headed households deploying extreme coping strategies. This is similar to the finding by Onah and Govender that female-headed households borrowed more often than male-headed households (5).

This study and many other studies $(3,18)$ from Nigeria, report that direct OOP payment is the most prevalent payment mechanism adopted by households in accessing needed healthcare. In addition, drawing from household savings is the most frequently adopted payment coping mechanism (Table 3 ) mainly because it is dependable, predictable and has no further costs attached. Formal or informal borrowing as well as begging for alms or charity are less frequently deployed. In other climes however, borrowing is reported as the most prevalent coping mechanism due to the near absence of household savings occasioned possibly by worse poverty, or due to the presence of a recognized social financial assistance framework (21). For reasons that may not be readily proffered, sale of assets, forfeiture of meals and postponement of defrayment of bills are rarely reported as payment coping strategies.

Further payment coping strategies beyond drawing from household savings are prevalently deployed by uninsured households to gain access to elective major surgical operations (Table 3; Fig. 1). About $61.4 \%$ of households that paid entirely by direct OOP payment deployed these further coping strategies. There is evidence from this study that compared with insured household, the uninsured household prevalently deploys one or more extreme coping strategies such as borrowing from unofficial and official sources $(\mathrm{p}=<0.001)$, begging for alms $(p=0.02)$, but not sale of valuable assets $(p=1.0)$, forfeiting food $(\mathrm{p}=0.60)$ and delayed defrayment of bills $(\mathrm{p}=1.0)$. This observation is irrespective of household socio-economic status (Table 4). 
Households that accessed NHIS for the needed surgery less frequently deployed any of these further payment coping strategies beyond drawing from household savings. These further strategies are not however eliminated. Correcting for other household characteristics, there is a 0.3 odds $(23.1 \%$ chance) that a household accessing NHIS for major surgical operation electively would deploy extreme payment coping strategies ( $95 \%$ CI $0.1-1.0 ; \mathrm{p}=0.05$; Table 4$)$. The study by Balasubramanian et al. (22) reveals that the introduction of Surgical Package Program (SPP) in some districts of India did not succeed in eliminating borrowing and drawing from savings in paying for costs associated with accessing needed surgical care. NHIS in Nigeria has succeeded in reducing, but not eliminating, deployment of extreme payment coping strategies in accessing major surgical operations. This apparently is due to significant co-payments and non-medical costs essentially similar to the finding from another community study in India by Dror et al., which shows that fewer households on community-based health insurance adopted borrowing to attend to direct non-medical costs associated with accessing needed healthcare when compared with households not covered by health insurance (23).

Formal education has the propensity to increase household's prompt use of healthcare services and products, and to decrease household's dependence on borrowing and charity (24). This agrees with the finding in this study that households with less educated heads have an 8.9 odds of deploying extreme coping strategies $(p=0.004)$. This may be because of an increased tendency for households with less educated heads to spend their limited funds initially seeking alternative unorthodox healthcare services out of ignorance and in the absence of firm regulations before eventually settling for orthodox care (25). Curiously, household socio-economic status quintiles, worked out using household durable assets and conditions of living, do not significantly influence deployment of these extreme payment coping strategies (OR $0.8 ; 95 \%$ CI $0.7-1.1 ; \mathrm{p}=0.19$; Table 4). This may be because the quintiles are really different levels of poverty, similar to observations made in other studies (6). An alternative explanation perhaps is that the relatively higher cost of surgical care means combining routine household income and drawing from savings are usually not enough in the absence of a robust social insurance on health irrespective of socio-economic status.

These findings are in line with the observation that extreme hardship financing of healthcare services is prevalent in low and medium income countries with high rate of direct OOP payment and poorly developed social insurance on health (18). Gaining access to major surgical operation through the current NHIS in Nigeria has been demonstrated to generally reduce household's deployment of payment coping strategies for co-payments and non-medical costs in accessing major surgeries electively. The reduction is particularly evident in the deployment of extreme coping strategies. In addition, the deployment of these extreme payment coping strategies is more prevalent among households with more than 6 adults, femaleheaded households and households with poorly educated heads. Notably, socio-economic status of households has not offered significant protection against hardship financing of major surgeries.

\section{Limitations of the study}

Selection bias is inherent in this study: the survey captures households that accessed major surgical operations from the said public tertiary hospital within the study period and without randomization. These may be households that possess inherent characteristics that make them accommodate the style of surgical care in public tertiary hospital settings, which expectedly differ from the style in private tertiary hospital settings as well as in primary and secondary hospital settings. In addition, the recall bias inherent in questionnaire-based surveys such as this study is a limitation to this study.

\section{Further research}

A wider national or regional multicentre study would illuminate this subject matter better for a robust policy statement.

\section{Acknowledgements}

We acknowledge Dr Anderson Aneke, Dr Solomon Anyimba, Dr Chisom Mbaeze and Dr Ekeoma Nwosu, resident doctors on training in the department of surgery, for their assistance with data collection.

\section{References}

1. Ivers LC, Garfein ES, Augustin J, et al. Increasing access to surgical services for the poor in rural Haiti: Aurgery as a public good for public health. World J Surg. 2008; 32(4):537-42.

2. Price R, Makasa E, Hollands M. World Health Assembly Resolution WHA68.15: Strengthening emergency and essential surgical care and anesthesia as a component of universal health coverage - addressing the public health gaps arising from lack of safe, affordable and accessible surgical and anesthetic services. World J surg. 2015; 39(9):2115-25.

3. Okoronkwo IL, Ekpemiro JN, Onwujekwe OE, et al. Socioeconomic inequities and payment coping mechanisms used in the treatment of type 2 diabetes mellitus in Nigeria. Niger J Clin Pract. 2016; 19(1):104-9.

4. Uzochukwu BSC, Ughasoro MD, Etiaba E, et al. Health care financing in Nigeria: Implications for achieving universal health coverage. Niger J Clin Pract. 2015; 18:437-44.

5. Onah MN, Govender V. Out-of-pocket payments, health care access and utilisation in south-eastern Nigeria: A gender perspective. PLoS One. 2014; 9(4): e93887.

6. Onwujekwe O, Hanson K, Uzochukwu B. Examining inequities in incidence catastrophic health expenditures on different healthcare services and health facilities in Nigeria. PLoS One. 2012; 7(7). e40811. 
7. Shrime MG, Dare AJ, Alkire BC, et al. Catastrophic expenditure to pay for surgery worldwide: A modeling study. Lancet Glob Health. 2015; 3 Suppl 2: S38-44.

8. Ravit M, Philibert A, Tourigny $\mathrm{C}$, et al. The hidden costs of a free Caesarean Section policy in West Africa (Kayes region, Mali). Matern Child Health J. 2015; 19(8):1734-43.

9. Madan J, Lönnroth K, Laokri S, et al. What can dissaving tell us about catastrophic costs? Linear and logistic regression analysis of the relationship between patient costs and financial coping strategies adopted by tuberculosis patients in Bangladesh, Tanzania and Bangalore, India. BMC Health Serv Res. 2015; $15: 476$

10. Hogue ME, Dasgupta SK, Naznin E, et al. Household coping strategies for delivery and related healthcare cost: Findings from rural Bangladesh. Trop Med Int Health. 20(10): 2015; 1368-75.

11. Kruk ME, Goldmann E, Galea S. Borrowing and selling to pay for health care in low- and middle-income countries. Health Aff. 2009; 28(4):1056-66.

12. Quintussi M, van de Poel E, Panda P, et al. Economic consequences of ill-health for households in northern rural India. BMC Health Serv Res. 2015; 15:179.

13. Aliyu AA, Amadu L. Urbanization, cities and health: The challenges to Nigeria. A review. Ann Afr Med. 2017; 16(4): 149-58.

14. Nigeria, UNDP. Human Development Report, Nigeria. 2008-2009. Abuja, Nigeria: United Nations Development Programme, 2009. www.nigerianstat.gov.ng Accessed 27 March 2018.

15. Ezeoke OP, Onwujekwe OE, Uzochukwu BC. Towards universal coverage: examining costs of illness, payment and coping strategies to different population groups in southeastern Nigeria. Am J Trop Med Hyg. 2012; 86(1):52-7.

16. Ukwaja KN, Alobu I, Lgwenyi C, et al. The high cost of free tuberculosis services: Patient and household costs associated with tuberculosis care in Ebonyi State, Nigeria. PloS One. 2013; 8(8):e73134.
17. Olugbenga-Bello AI, Adebimpe WO. Knowledge and attitude of civil servants in Osun State, southwestern Nigeria, towards the national health insurance. Niger J Clin Pract. 2010; 13(4):421-6.

18. Dienye PO, Brisibe SF, Eke R. Sources of healthcare financing among surgical patients in a rural Niger Delta practice in Nigeria. Rural Remote Health. 2011; 11(2):1577.

19. Etiaba E, Onwujekwe O, Uzochukwu B, et al. Investigating payment coping mechanisms used for the treatment of uncomplicated malaria to different socio-economic groups in Nigeria. Afr Health Sci. 2015; 15(1):42-8.

20. Adisa O. Investigating determinants of catastrophic health spending among poorly insured elderly households in urban Nigeria. Int J Equity Health. 2015; 14:79.

21. Palmer M, Groce N, Mont D, et al. The economic lives of people with disabilities in Vietnam. PLoS One. 2015; 10(7): e0133623.

22. Balasubramanian D, Prinja S, Aggarwal AK. Effect of user charges on secondary level surgical care utilization and outof-pocket expenditures in Haryana state, India. PLoS One. 2015; 10(5): e0125202.

23. Dror DM, Chakraborty A, Majumdar A, et al. Impact of community-based health insurance in rural India on selfmedication and financial protection of the insured. Indian $\mathrm{J}$ Med Res. 2016; 143(6):809-20.

24. Vallières F, Hansen A, McAuliffe E, et al. Head of household education level as a factor influencing whether delivery takes place in the presence of a skilled birth attendant in Busia, Uganda: A cross-sectional household study. BMC Pregnancy Childbirth. 2013; 13:48.

25. Okafor IP, Sekoni AO, Ezeiru SS, et al. Orthodox versus unorthodox care: A qualitative study on where rural women seek healthcare during pregnancy and childbirth in southwest, Nigeria. Malawi Med J. 2014; 26(2):45-9. 